\title{
Оценка безопасности проведения радиочастотной катетерной деструкции фибрилляции предсердий катетерами с дистальным электродом 4 мм без функции охлаждения
}

\author{
Доронин А. В. ${ }^{1}$, Суслина Ю. И. ${ }^{2}$, Резник А. С. ${ }^{2}$, Ханенова В.А. ${ }^{2}$, \\ Марушко Е. Ю.' ${ }^{2}$ Мешкова М. С. ${ }^{2}$ \\ ${ }^{1}$ Национальная медицинская академия последипломного образования имени П. Л. Шупика (Киев) \\ 2 ГУ «Научно-практический медицинский центр детской кардиологии \\ и кардиохирургии МЗ Украины» (Киев)
}

\begin{abstract}
В статье анализируется собственный опыт катетерного устранения фибрилляции предсердий (ФП) обычными электродами. Проанализированы осложнения 500 последовательных процедур, проведенных в период с 01.2013 г. по 12.2016 г. в ГУ «НПМЦДКК МЗ Украины». Первичные и повторные процедуры осуществлядись без проведения навигационных систем. После 15-20 аппликаций деструкционный электрод извлекался и протирался.

Средний возраст больных составил $55,7 \pm 10,8$ года. У пациентов с пароксизмальной формой ФП произведено $304(60,8 \%)$ процедуры, непароксизмальной - 196 (39,2\%). Первичные процедуры проведены у $396(79,2 \%)$ пациентов, 89 (17,8\%) процедур произведено повторно, $13(2,6 \%)$ - третий раз, $2(0,4 \%)-$ четвертый.

Зафиксировано $8(1,6 \%)$ значимых осложнений: тампонада перикарда $-2(0,4 \%)$, аневризма бедренной артерии $-4(0,8 \%)$, артериовенозная фистула $-1(0,2 \%)$, гематома в месте пункции $-1(0,2 \%)$. Также зафиксировано $5(1,0 \%)$ случаев выпота в перикарде и $1(0,2 \%)$ случай транзиторной атриовентрикулярной блокады.

Таким образом, количество осложнений при использовании обычных электродов не выше, чем при использовании электродов с функцией охлаждения.
\end{abstract}

Ключевые слова: фибрилляция предсердий, катетерная деструкция, осложнения.

Радиочастотная катетерная деструкция фибрилляции предсердий (ФП) в клиниках, обладающих достаточным опытом, является эффективной и безопасной процедурой [1]. Частота осложнений в таких клиниках составляет 2-3\%: осложнения, связанные с пункцией сосудов, составляют $1-2 \%$, с перфорацией сердца $-0,5-1 \%$, тромбоэмболией $-0,5-1 \%$. Смертность составляет менее $0,1 \%$ [2]. В клиниках, обладающих меньшим опытом, частота осложнений может достигать 7-10\% [3].

Осложнения делят на большие и малые. К большим осложнениям относят госпитальную летальность, массивное кровотечение, потребовавшее оперативного вмешательства, артериовенозную фистулу, потребовавшую оперативного вмешательства, дислокацию электрода электрокардиостимулятора, выраженную анемию, повреждение диафрагмального нерва, тромбоэмболию и полную АВ-блокаду. Малые осложнения - выпот в перикарде, гематома в месте пункции подключичной или югулярной вены, транзиторная AB-блокада, ятрогенная блокада ножки пучка Гиса или транзиторная элевация сегмента ST [4].

До 2006 года для катетерной деструкции ФП применялись исключительно электроды без функции охлаждения. Затем начали использовать охлаждаемые электроды с целью снижения вероятности осложнений. Однако до сих пор не получено четких доказательств того, что электроды с функцией охлаждения действительно делают катетерную деструкция ФП более безопасной [5].

Цель работы - проанализировать осложнения, возникшие при катетерном лечении ФП электродами без функции охлаждения, и сравнить их с данными литературы.

Материалы и методы. В период с 01.2013 г. по 12.2016 г. в ГУ «Научно-практический медицинский центр детской кардиологии и кардиохирургии МЗ Украины» было произведено 500 последовательных катетерных деструкций ФП. У пациентов с пароксизмальной формой ФП проведено $304(60,8 \%)$ процедуры, непароксизмальной - 196 (39,2\%).

В группе была 41 женщина. Средний возраст со- 


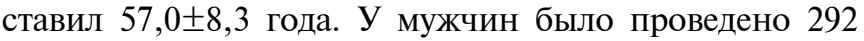
$(58,4 \%)$ процедуры. Всем пациентам проводилась четырехнедельная подготовка антикоагулянтами. Антиаритмическая терапия перед процедурой не отменялась.

Устранение аритмии осуществлялось под интубационным наркозом, через двойную транссептальную пункцию, которая выполнялась под чреспищеводным ультразвуковым контролем. Всем пациентам производилась изоляция легочных вен обычными катетерами с дистальным электродом 4 мм без функции охлаждения с использованием электродов «Lasso». После каждых 15-20 аппликаций деструкционный электрод извлекался и протирался влажной салфеткой, транссептальный катетер промывался физиологическим раствором с добавлением гепарина.

Пациентам с непароксизмальной формой ФП дополнительно наносились аппликации в правом и левом предсердии в местах регистрации необычных предсердных электрограмм на синусовом ритме или «фрагментированных потенциалов» на ФП. Наносилась линия аппликаций между полыми венами. После этого, в случае отсутствия синусового ритма, проводилась ЭИТ.

Мощность воздействия не превышала 35 Ватт, температура $-55^{\circ} \mathrm{C}$, время аппликации -40 секунд.

Результаты. Первичные процедуры проведены у 396 $(79,2 \%)$ пациентов, 89 (17,8\%) процедур произведено повторно, 13 (2,6\%) - третий раз, $2(0,4 \%)$ - четвертый.

Зафиксировано 8 (1,6\%) больших осложнений:

\section{Таблица 1}

Осложнения катетерной деструкции ФП

\begin{tabular}{lccc} 
& $\begin{array}{c}\text { Данные } \\
\text { литературы } \\
\text { (n=1000-20825) }\end{array}$ & \multicolumn{2}{c}{$\begin{array}{c}\text { Собственные } \\
\text { данные } \\
\text { (n=500) }\end{array}$} \\
\cline { 2 - 5 } Осложнения & $\mathbf{n}$ & $\mathbf{n}$ & $\%$ \\
\hline $\begin{array}{l}\text { Тромбоэмболии } \\
\text { и инсульты }\end{array}$ & $0,3-0,7 \%$ & 0 & 0 \\
\hline Тампонада перикарда & $0,3-1,3 \%$ & 2 & 0,4 \\
\hline $\begin{array}{l}\text { Симптоматический стеноз } \\
\text { легочных вен }\end{array}$ & $0,1-1,1 \%$ & 0 & 0 \\
\hline $\begin{array}{l}\text { Предсердно-пищеводная } \\
\text { фистула }\end{array}$ & $0-0,2 \%$ & 0 & 0 \\
\hline $\begin{array}{l}\text { Перипроцедуральная } \\
\text { смерть }\end{array}$ & $0,05-0,2 \%$ & 0 & 0 \\
\hline $\begin{array}{l}\text { Общее количество } \\
\text { больших осложнений }\end{array}$ & $2,7-4,5 \%$ & 8 & 1,6
\end{tabular}

тампонада перикарда, потребовавшая перикардиоцентеза, $-2(0,4 \%)$, аневризма бедренной артерии с необходимостью проведения пластики артерии - 4 (0,8\%), артериовенозная фистула, которая разрешилась консервативно, $-1(0,2 \%)$, гематома в месте пункции, потребовавшая переливания крови, $-1(0,2 \%)$. Зафиксировано также $5(1,0 \%)$ случаев выпота в перикарде, разрешившихся консервативно, и $1(0,2 \%)$ транзиторная AВ-блокада (АВ-проводимость восстановилась через 2 часа). Таким образом, большинство осложнений было связано либо с пункцией сосудов, либо с транссептальной пункцией. Осложнений, которые можно было связать с использованием электродов без функции охлаждения, зафиксировано не было.

Мы сравнили собственные осложнения с данными литературы. Результаты приведены в табл. 1 [1-6]. Видно, что удельный вес осложнений у нашей группы пациентов не превышает аналогичные показатели ведущих клиник мира.

Выводы. Утверждение о том, что электроды с функцией охлаждения повышают безопасность катетерной деструкции ФП, в нашем исследовании не нашло своего подтверждения. Очевидно, что необходимы дальнейшие исследования, которые включали бы большее число пациентов. Но и полученные данные позволяют утверждать, что применение для катетерной деструкции ФП электродов без функции охлаждения является достаточно безопасным. Однако на количество осложнений могут влиять и другие элементы предложенной нами методики, что также требует дальнейшего изучения.

\section{Литература}

1. Updated worldwide survey on the methods, efficacy, and safety of catheter ablation for human atrial fibrillation / R. Cappato, H. Calkins, S. A. Chen et al. // Circ. Arrhythm. Electrophysiol. - 2010. - Vol. 3. - P. 32-38.

2. Buch E., Shivkumar K. Catheter Ablation of Atrial Fibrillation Advent of Second-Generation Technologies // Journal of the American college of cardiology. - 2015. Vol. 66. - N. 12. - P. 1361-1363.

3. Ghosh J. M., Mcguire M. A. The Full Circle: Back into the Pulmonary Veins: A New Possibility in AF Ablation? // J Cardiovasc Electrophysiol. - September 2015. - Vol. 26. P. 1007-1008.

4. Anderson K. P. Ablation for atrial fibrillation: what are acceptable levels of experience, efficacy, and complications? // J Interv Card Electrophysiol. - 2012. Vol. 34. - P. 125-128.

5. Hindriks G. All you want to know about ablation // Crossing Borders. - 2015. - № 12. - YouTube. 


\title{
The safety evaluationofthe atrial fibrillation radiofrequency catheter ablations with non-irrigated $4 \mathrm{~mm}$ tip catheters use
}

\author{
Doronin A. ${ }^{2}$, Suslina J. ${ }^{1}$, Riznyk A. ${ }^{1}$, Khanenova V. ${ }^{1}$, Marushko Y. ${ }^{1}$, Meshkova M. ${ }^{1}$ \\ ${ }^{1}$ Ukrainian Children's Cardiac Center (Kyiv) \\ 2 Ukrainian National Medical Postgraduate Academy (Kyiv)
}

The article analyzes own experience of catheter ablation to eliminate atrial fibrillation (AF) by conventional electrodes. We analyzed the complications of 500 consecutive procedures carried out in the period from 01.2013 till 12.2016, in the UCCC. Initial and repeat procedures were performed without navigation system. After 15-20 applications destructive electrode was removed and wiped.

The average age of patients was $55,7 \pm 10,8$ years. In patients with paroxysmal AF we produced $304(60.8 \%)$ procedures, in perisitent $-196(39.2 \%)$. Initial treatments conducted at $396(79.2 \%)$ patients, $89(17.8 \%)$ procedures performed repeatedly, in $13(2.6 \%)$ - third time, and in $2(0.4 \%)$ - the fourth.

Fixed $8(1.6 \%)$ significant complications: pericardial tamponade $-2(0.4 \%)$, femoral artery aneurysm $-4(0.8 \%)$, the atrio-venous fistula $-1(0.2 \%)$, hematoma at the site of puncture $-1(0.2 \%)$. Also recognized $5(1.0 \%)$ cases of pericardial effusion, and $1(0.2 \%)$ - transient atrioventricular block.

Thus, the number of complications in the use of conventional electrodes is not higher than when using electrodes with a cooling function.

Key words: atrial fibrillation, catheter degradation, complications.

\section{Оцінка безпеки проведення радіочастотної катетерної деструкції фібриляції передсердь катетером з дистальним електродом 4 мм без функції охолодження}

\author{
Доронін О. В. ${ }^{1}$, Сусліна Ю. І. ${ }^{2}$, Різник О. С. ${ }^{2}$, Ханенова В.А. ${ }^{2}$, Марушко $Є$. Ю. ${ }^{2}$, Мешкова М. С. ${ }^{2}$ \\ ${ }^{1}$ Національна медична академія післядипломної освіти імені П. Л. Шупика (Київ) \\ ${ }^{2}$ ДУ «Науково-практичний медичний центр дитячої кардіології та кардіохирургії МОЗ України» (Київ)
}

У статті аналізується власний досвід катетерного усунення фібриляції передсердь (ФП) звичайними електродами. Проаналізовано ускладнення 500 послідовних процедур, проведених у період з 01.2013 р. по 12.2016 р. в ДУ «НПМЦДКК МОЗ України». Первинні та повторні процедури здійснювалися без проведення навігаційних систем. Після 15-20 аплікацій деструкційний електрод витягувався і протирався.

Середній вік хворих становив $55,7 \pm 10,8$ року. У пацієнтів із пароксизмальною формою ФП здійснено 304 $(60,8 \%)$ процедури, з непароксизмальною - 196 (39,2\%). Первинні процедури проведені у 396 (79,2\%) пацієнтів, $89(17,8 \%)$ процедур виконано повторно, $13(2,6 \%)$ - третій раз, 2 (0,4\%) - четвертий.

Було зафіксовано $8(1,6 \%)$ значущих ускладнень: тампонада перикарда - $2(0,4 \%)$, аневризма стегнової артеpiï - $4(0,8 \%)$, артеріовенозна фістула - $1(0,2 \%)$, гематома в місці пункції - $1(0,2 \%)$. Також зафіксовано $5(1,0 \%)$ випадків випоту в перикард і $1(0,2 \%)$ випадок - транзиторної атріовентрикулярної блокади.

Таким чином, кількість ускладнень при використанні звичайних електродів не вища, ніж при використанні електродів із функцією охолодження.

Ключові слова: фібриляція передсердь, катетерна деструкція, ускладнення. 